\title{
Um novo olhar sobre participação da família no processo terapêutico
}

\section{A new view on the family participation in the therapeutic process}

\author{
Rosana Carla do Nascimento Givigi ${ }^{1}$, Analu Siqueira Santos ${ }^{2}$, \\ Gláucia Oliveira Ramos ${ }^{3}$
}

\begin{abstract}
GIVIGI, R. C. N.; SANTOS, A. S.; RAMOS, G. O. Um novo olhar sobre participação da família no processo terapêutico. Rev. Ter. Ocup. Univ. São Paulo, v. 22, n. 3, p. 221-228, set./dez. 2011.

RESUMO: Esse estudo teve o objetivo de incluir a família no processo terapêutico de crianças com paralisia cerebral e analisar os efeitos dessa inclusão. Metodologicamente foi feito um estudo de caso com duas crianças com idades de quatro e oito anos, que apresentavam o quadro de paralisia cerebral em diferentes tipos e graus. A intervenção fonoaudiológica ocorreu durante oito meses, uma vez por semana. Ao final desse período aponta-se a maior credibilidade e envolvimento da família na terapia; abertura do diálogo; identificação das respostas dos pacientes; o paciente pode aparecer como sujeito. Conclui-se que para o processo terapêutico com crianças, a inclusão da família é essencial, sendo a clínica um espaço de escuta.
\end{abstract}

DESCRITORES: Família/psicologia; Terapia familiar; Crianças com problemas/psicologia; Fonoaudiologia.

\footnotetext{
1. Prof ${ }^{\mathrm{a}}$. Adjunta da Universidade Federal de Sergipe - UFS, curso de Fonoaudiologia.

2. Aluna da graduação em Fonoaudiologia - Iniciação Científica - Universidade Federal de Sergipe - UFS.

3. Aluna da graduação em Fonoaudiologia - Iniciação Científica - Universidade Federal de Sergipe - UFS.

Endereço para correspondência: Av: Augusto Franco, 3500, casa 55, Ponto Novo, Aracaju, SE. CEP: 49097-670. E-mail; rgivigi@uol. $\underline{\text { com.br }}$
} 


\section{INTRODUÇÃO}

$\mathrm{O}$

trabalho com a família tem sido campo de interesse de muitas áreas, como a psicologia, a fonoaudiologia, a educação, dentre outras.

Porém, ela pode ser investigada e analisada de diferentes formas. Independente da visão e do lugar que ocupe para essas áreas ela é considerada a primeira das redes da criança e por isso interfere de forma direta no desenvolvimento seja na constituição do sujeito, da constituição da linguagem ou do desenvolvimento geral.

Se num primeiro momento a mãe tem que se adaptar a nova rotina, pois sua vida passa a girar em torno do bebê, é ela também quem precisa sustentá-lo física e psiquicamente (WINNICOTT, 1991).

Esse extenso processo de vinculação entre mãe e bebê se denomina simbiose. Porém, o próprio desenvolvimento do bebê vai assegurando a quebra dessa relação, à custa de muita angústia causada pela separação, mas que será propulsora de importante desenvolvimento para criança (KERTÉSZ; INDUNI, 1977).

Por volta de dois anos essa dependência passa a ser relativa e torna-se crescente o desenvolvimento da autonomia da criança. Diante de um filho com deficiência as funções parentais assumem um novo lugar, demarcado inicialmente pelo medo, pela quebra do sonho. Depois ancorada no desenvolvimento, que habitualmente não acontece da mesma maneira, assim não se constrói a percepção de que o filho pode se manter numa certa independência (WINNICOTT, 1991).

Muitos trabalhos destacam como é difícil para mãe de crianças com deficiências romper o vínculo simbiótico, o que prejudicaria o desenvolvimento lingüístico-psíquico e cognitivo da criança (HENN et al., 2008).

Portanto, o trabalho com a família torna-se importante para profissionais que lidam diretamente com o desenvolvimento infantil. Esse estudo buscou incluir a família no processo terapêutico de crianças com paralisia cerebral e analisar os efeitos dessa inclusão.

\section{REFLETINDO SOBRE O LUGAR DA FAMÍLIA NA CLÍNICA}

O presente artigo busca discutir a relação terapêutica com famílias de crianças com paralisia cerebral. Para Bobath (1990) a paralisia cerebral é conceituada como uma desordem do movimento e da postura devido a um defeito ou lesão do cérebro imaturo. Essa lesão não é progressiva e provoca debilitação variável na coordenação da ação muscular e resulta na incapacidade da criança em manter a postura e realizar movimentos normais. A lesão afeta o cérebro imaturo e interfere na maturação do SNC, o que leva a consequências específicas em termos do tipo de paralisia cerebral desenvolvida. Embora a lesão que causa a paralisia cerebral seja estável o quadro clínico pode mudar ao longo do tempo devido à plasticidade cerebral. A regulação automática da motricidade sempre está alterada, mas em diferentes graus sendo demonstrado pelo exame clínico (BOBATH, 1990).

Nesse cenário, o fonoaudiólogo irá trabalhar com as alterações miofuncionais orofaciais e com os aspectos linguísticos da criança com paralisia cerebral. Esse trabalho visa estimular e melhorar o desempenho das estruturas orofaciais com o objetivo de facilitar as funções de respiração, alimentação e fala além da postura mais adequada para organização dessas funções (LIMONGI, 2003).

A família é um sistema relacional interdependente, complexo e articulado. Nesse sistema, que é responsável pelo crescimento e desenvolvimento do indivíduo, observa-se que as redes construídas podem fazer com que os membros envolvidos contagiem, com suas angústias e sofrimentos, os que dele fazem parte (GOMES, 2005; GALHEIGO; ANGELI, 2008; LAMELA et. al., 2010).

De acordo com Givigi (2007), essas redes têm uma estrutura de conexão instável entre elementos que estão permanentemente em interação, mas que obedecem a normas de funcionamento. Essa interconexão instável permite que as mudanças aconteçam como em um sistema dinâmico que está em constante movimento.

Gomes (2005) afirma que na tentativa de manter sua identidade de grupo a família tende a manter seus padrões de interação em confronto com dados da realidade. Para enfrentar mudanças é preciso suportar os desequilíbrios, os conflitos, os medos que fazem parte dos momentos de transição entre um modo de funcionar, conhecido e seguro, para outro desconhecido e ameaçador.

De acordo com Val et al. (2005) as terapias fonoaudiológica, fisioterápica e psicológica são importantes para a criança com paralisia cerebral e assumem os objetivos relacionados ao desenvolvimento de atividades funcionais relacionadas aos problemas apresentados pelas crianças. Mas as crianças permanecem a maior parte do tempo em casa, daí a importância da participação dos pais no processo terapêutico que pode contribuir no desenvolvimento das atividades e capacidades da criança.

Assim a família é entendida como integrante do processo terapêutico, não mais como coadjuvante do terapeuta. Esse olhar se movimenta para compreensão do 
lugar que a criança ocupa neste meio, as formas que estas relações são estabelecidas e como a família lida com a patologia. Givigi (2007) propõe que a relação entre terapeuta e família contemple e acolha as demandas familiares e não se restrinja apenas ao trabalho de orientação.

A família pode assim assegurar e participar do processo terapêutico de diferentes formas. A confiança mútua desenvolvida entre os membros que fazem parte do processo que o tornam criador de possibilidades e permitem ao terapeuta a visão privilegiada sobre o lugar do sujeito na família e as possibilidades de mudança. Nesse trabalho com a família o fonoaudiólogo se coloca como mediador e não como instrutor (GIVIGI, 2007).

Mediador é aqui entendido como "aquele que faz parte", desenvolvendo o trabalho em uma relação horizontal.

\section{METODOLOGIA}

Para realização desse estudo foi adotada a abordagem qualitativa, que permitiu a compreensão da realidade de forma complexa, por meio do desenvolvimento de um estudo de caso, que visou a análise em profundidade e a busca da compreensão do fenômeno estudado.

Enfim este estudo de caso buscou contribuir para o desenvolvimento da área do conhecimento em questão, ampliando o entendimento sobre o fenômeno aqui estudado (YIN, 2002).

Como estudo descritivo, utilizou também a pesquisa-ação. As duas abordagens metodológicas são complementares nesse trabalho. A pesquisa-ação foi usada como estratégia de intervenção. Trata-se de pensar a ação tomando como alicerce a teoria, de modo que sempre se esteja agindo em espiral, numa reflexão permanente sobre a ação. Nesse processo, todos os participantes, inclusive o pesquisador, devem envolver-se nas questões postas. Para isso, compreende que a realidade é complexa e dinâmica e deve-se aprende a lidar com os confrontos e contradições (BARBIER, 2004).

\section{Seleção dos sujeitos}

O estudo foi desenvolvido no Laboratório de Pesquisa em Linguagem da Universidade Federal de Sergipe, no período de janeiro de 2010 a agosto de 2010. Foram selecionadas crianças com diagnóstico médico de paralisia cerebral e com dificuldades alimentares. As crianças faziam parte do grupo de pesquisa "A Construção da linguagem, patologias e a prática clínica". A escolha dos sujeitos justificou-se pelo diagnóstico e pelas diferenças nas famílias, o que enriqueceu a análise. Foi dirigido convite às mães e explicado em que consistiria o trabalho, sua duração e objetivos. Após o aceite em participar foi agendada a entrevista inicial.

Foi utilizada a entrevista semi-estruturada, caracterizada por poucas perguntas diretas e certa liberdade do pesquisador e do entrevistado. Desta forma, seria possível perceber as relações familiares que dão forma e sentido às questões apresentadas pelas crianças.

A pesquisa foi aprovada pelo Comitê de Ética em Pesquisa da UFS, com o protocolo de número CAAE 0131.0.107.000-08. Todos os participantes assinaram o Termo de Consentimento Livre e Esclarecido.

\section{Apresentação dos sujeitos}

Y. de 08 anos, filho único, possui pais separados e mora sozinho com a mãe. Frequenta a escola regular dois dias na semana. Em relação ao processo terapêutico, inicialmente sua mãe permaneceu com pouca participação dentro do setting. Y. possui o intelecto preservado, com ótima compreensão. Tem diagnóstico de paralisia cerebral espástica quadriplégica severa.

V. de 04 anos, segunda filha de um casal que vive conjuntamente, mora na sua casa com seus pais e mais dois irmãos, um mais velho e outra mais nova. Frequenta escola regular todos os dias da semana e participa de todas as atividades na sala de aula. Sua família era bastante participativa e dinâmica no que diz respeito ao processo terapêutico de V. No processo de interação na terapia mostrava que compreendia pelo sorriso. Tem o diagnóstico de paralisia cerebral mista quadriplégica severa.

\section{Procedimentos}

Primeiramente, foi realizada a entrevista inicial individual com a mãe de cada criança. Nela considerou importante que as mães expusessem as informações que acreditavam ser relevantes, mas em determinados momentos foram feitas intervenções na busca de questões importantes para o estudo. Nessas entrevistas foram obtidas informações referentes à história de vida da criança.

Posteriormente foi feita a avaliação específica, para obter dados referentes a aspectos do processo de alimentação, postura corporal da criança e condições anatomofuncionais do Sistema Estomatognático, que compõem o protocolo de avaliação do sistema estomatognático utilizado no LIFSASM (VAL et al., 2005).

A avaliação foi realizada em três momentos: o $1^{\circ}$ na sala de atendimento avaliação indireta, sem a apresentação 
de alimentos, o $2^{\circ}$ momento na casa da criança, na hora do almoço, em avaliação direta com apresentação de alimentos oferecidos pela mãe e o $3^{\circ}$ momento ocorreu na sala de atendimento com avaliação das funções estomatognáticas. A avaliação foi realizada em quatro sessões, com duração de 50 minutos, uma vez por semana.

A intervenção fonoaudiológica se deu durante o período de oito meses. Foi feito o trabalho com a família e a terapia com as crianças pesquisadas. A intervenção foi semanal, com sessões individuais de 50 minutos. Foram no total 15 sessões com $\mathrm{Y}$ e 13 sessões com V..

O trabalho com a família aconteceu em três etapas, a entrevista inicial, a participação das mães do processo terapêutico e a entrevista final. Cabe ressaltar que inicialmente as mães não permaneciam na sala de atendimento, mas o trabalho também consistia em trazêlas à sessão terapêutica e depois permaneceram durante a maioria dos atendimentos. No trabalho era explicado para as mães todos os procedimentos, a fim de oportunizar a participação delas no processo terapêutico. Durante todo percurso o diálogo foi o dispositivo de trabalho com a família, especialmente quando se referia a ações cotidianas como à adequação postural durante a alimentação, a adequação de utensílios utilizados em seu cotidiano, dentre outros. Durante o processo terapêutico, foi abordado o trabalho de adequação das estruturas orofaciais quanto ao tônus, mobilidade, postura, estímulos das funções estomatognáticas, envolvimento da família quanto aos cuidados necessários na alimentação e interação entre as terapeutas e as crianças (VAL et al., 2005).

A opção foi trabalhar numa abordagem horizontal, pois dessa forma haveria o afastamento do lugar do "terapeuta detentor do saber" e seria reconhecido que cada pessoa envolvida no processo (família, terapeuta e paciente) contribui de alguma forma para o sucesso terapêutico.

\section{DISCUSSÃO E RESULTADOS}

Criança e família, aqui representada pela figura da mãe, tecem uma rede de interdependência e esta por sua vez gera mútuas influências, pois a mesma possui uma infinidade de ligações, isto implica dizer que se um integrante da família sofre por um motivo qualquer, todo esse sistema que o compõe sofrerá alguma transformação. $\mathrm{O}$ ponto de partida para o trabalho foi entrevista inicial com o desejo de conhecer as crianças e seu lugar na família através do discurso da mãe, acreditando, porém que, aquilo que é dito traz memórias de como as relações são constituídas. Uma mesma situação pode ser vista e significada de diferentes formas, porém essa leitura e significação não são estáveis, elas podem ser modificadas (BAKTHIN, 1997). A permissão para esse processo de mudanças vai sendo possível por meio da confiança construída e da relação estabelecida, foi o que aconteceu com uma das famílias que mais adiante vocês conhecerão a trajetória.

\section{Processo terapêutico e resultados do trabalho com Y e sua família}

Este trabalho teve como base a construção de relações, optou-se por iniciar a intervenção terapêutica buscando construir um processo de interação com Y. Foram realizados três encontros que objetivaram antes de tudo conhecer o funcionamento de Y. enquanto sujeito. Com esses atendimentos conheceu-se coisas importantes em Y., por exemplo, preferências alimentares e brincadeiras, que sua forma de comunicação se dava através do piscar de olhos, que ao falar com o mesmo deveríamos manter sempre a mesma entonação vocal e falar com baixa intensidade a fim de não disparar os espasmos e também a posição correta de postura.

Como relatado anteriormente, Y. apresentava paralisia cerebral espástica quadriplégica severa com importante comprometimento motor, não possuía sustentação de pescoço, conseguia segurar apenas objetos que cabiam por inteiro na sua mão. $\mathrm{O}$ primeiro contato com Y. e sua mãe, se deu por meio entrevista inicial, e nesta, tínhamos o objetivo de conhecer a criança por meio do olhar da mãe. De início foi feita uma pergunta disparadora, solicitando que a mãe contasse sobre seu filho. Esta subitamente contou que Y. passava maior parte do dia deitado no colchão, vendo TV, sempre sozinho, pois a mesma não tinha tempo para brincar com ele. Revelou também que toda sua vida era dedicada exclusivamente aos cuidados com Y. Ao ser questionada sobre a questão alimentar de Y. relatou que este não possuía qualquer dificuldade alimentar, comia tudo, não engasgava, mastigava bem, ingeria líquido normalmente, não babava, dormia tranquilo, não roncava, sucção era normal e relatava que apenas sua respiração apresentava-se com um cansaço.

Diante do relato analisou-se que existem inúmeras formas de ver e sentir determinada situação e que essas formas eram construídas a partir de vários referenciais. Após a conversa com a mãe uma questão inquietava: $\mathrm{O}$ que levava a mãe a ver que o seu filho executava todas as funções sem dificuldades? Talvez, expressasse uma adaptação a sua realidade, de dedicação a educação do filho. A forma como executava suas funções era considerada 
normal para ela, por até então não conhecer outra maneira. Ou poderia ser o discurso de alguém que tenta afirmar as possibilidades do filho, não problematizando suas dificuldades. Todavia entende-se que não existe fala uniforme, que os discursos circulam e trazem marcas de muitas memórias, isso não era diferente nos dizeres da mãe, suas falas traziam marcas de uma realidade e de desejos que nem sempre eram fáceis de concretizar.

Considerando essas marcas do discurso a realização das sessões sempre buscavam novas formas de conhecer Y. Ele vinha para as sessões com assiduidade, sempre acompanhado da sua mãe, era muito assíduo, não foi difícil construir uma relação com ele. Em pouco tempo Y. animava-se ao entrar na sala para mais uma sessão. O trabalho tinha como objetivo trazer a família, representada pela mãe da criança para participar do processo terapêutico, pois segundo Abbud e Santos (2002), o relacionamento harmonioso entre o terapeuta e o paciente, e entre a família e o terapeuta criará um ambiente favorável à confiança entre todos os envolvidos no processo. É com essa mútua confiança e com a certeza de que as partes envolvidas (profissional, família e criança) estejam comprometidas com o trabalho que se estabelecerá o vínculo, essencial ao sucesso terapêutico. Construído o vínculo, a família estará mais disponível para, por meio das trocas com o profissional, compreender e participar de modo construtivo no desenvolvimento do processo de seu filho. A parceria estará selada, e será o paciente que receberá os benefícios dessa parceria.

Foi o que aconteceu com E. mãe de Y., no começo sempre deixava seu filho na sala de terapia e saia, sem que fosse pedido, e quando era solicitada a sua presença ela sempre dizia ter algo a fazer do lado de fora. Aos poucos com a relação sendo construída, esta foi permitindo o diálogo e aparecia a importância da sua presença naquele processo.

Cada procedimento e seus possíveis benefícios era explicado para a mãe. Pode-se dizer que ao tentar compreender a função que a mãe ocupava e os sentidos que atribuía a seu filho e a terapia, pode-se compreender como deveria acontecer o diálogo. Durante todo percurso a participação da mãe nas sessões foi importante para construção da parceria.

Foi feita a primeira visita domiciliar com o intuito de observar como era o processo de alimentação diário da criança. O combinado com a mãe é que seria na hora do almoço e nos esperasse para alimentá-lo, pois nosso desejo era ver como o alimentava. $\mathrm{O}$ almoço continha: feijão, arroz e carne, em consistência normal, que segundo a mãe eram alimentos habituais dessa família. A mãe posicionou-o adequadamente e o alimentou, mas ao ser interrogada se ela o alimentava sempre assim, esta relatou que raramente o posicionava daquela forma, apesar de saber que era a correta, pois considerava mais fácil alimentá-lo deitado. Essa visita trouxe uma aproximação entre terapeuta e família, e também da realidade dessa criança.

Nesta visita E. relatou que embora soubesse qual a melhor maneira de posicionar Y. ela não o fazia, pois considerava mais fácil alimentá-lo deitado, isto era facilmente entendido por qualquer pessoa, visto o tempo que E. passava para alimentar Y. Durante as sessões seguintes as conversas sobre alimentação foram ampliadas e foi explicado a ela que, embora fosse mais rápido, trazia mais riscos para Y., pois ele poderia aspirar a comida. O diálogo era importante para a mudança nos hábitos da mãe, mas ele não agia sozinho, a mãe participava dos atendimentos, via os procedimentos e seus resultados. A cada nova sessão relatava seu esforço para alimentá-lo da maneira correta:

\footnotetext{
"Essa semana consegui dar comida a ele sentado duas vezes só, mas já é alguma coisa não é?" (05/05/2010; $9^{\circ}$ encontro).

Outro dia...

"Dessa vez consegui mais vezes, eu não dou todo dia porque ele demora muito e as vezes é corrido, mas sempre que posso eu to dando sentado" (02/06/2010; $13^{\circ}$ encontro).

E mais adiante...

"Estou dando comida a ele sentado na hora do almoço e só as vezes no jantar, porque a noite ele ta cansado e dorme $\operatorname{logo...} "\left(20 / 07 / 2010 ; 15^{\circ}\right.$ encontro).
}

E. não só foi modificando a maneira de pensar, como também percebendo as sutis mudanças com essa nova forma de alimentar, no início dizia não notar diferença funcional entre alimentar Y. deitado ou sentado e nem mudança nas funções, uma vez que considerava que ele fazia tudo "perfeito". Na última entrevista, disse perceber uma melhora na mastigação, "está derrubando menos comida". Sobre a deglutição relatou que ele estava engasgando menos durante as refeições.

A participação da mãe no processo terapêutico fez com que seu olhar se modificasse. Se num primeiro momento apresentou-se como uma informante, com a presença durante as sessões seu olhar sobre as possibilidades de seu filho foi modificando, dentre os aspectos percebidos podemos destacar: mudança na forma de alimentar; oferecimento de mais tipos de alimentos; escuta diferenciada a forma de 
comunicação de Y.; criação do vínculo família e terapeuta.

A relação construída com a mãe permitiu que, enquanto terapeutas, houvesse interferência no funcionamento da família e assim aconteceram as modificações de atitudes e dos olhares da mãe sobre seu filho. Não foi fácil construir a relação com E., esta dava pouco espaço para intervir, talvez pela própria forma de ser, e se constituir. Constatou-se que o trabalho deve ser contínuo, junto as famílias e as crianças, pois a interação é sempre processual (SOUZA; SANTOS, 2010).

\section{Processo Terapêutico e resultados do trabalho com V. e sua família}

A relação com V. se deu de forma diferente de Y. Antes de iniciar a avaliação das funções buscouse conhecer, primeiramente o funcionamento de V. enquanto sujeito. Nos primeiros encontros compareceram características importantes de V., como sua forma de se comunicar, do que gostava de brincar, as coisas que the agradavam e as que não agradavam. A partir de então, iniciou-se a construção da relação, que se deu lentamente, pois o início da trajetória com V. foi marcado pelo choro que se manteve durante duas sessões e na primeira vista domiciliar. $\mathrm{O}$ choro era incessante e com algumas pausas. Utilizou-se a brincadeira simbólica como estratégia, possibilitando dessa maneira a criação de vínculo entre terapeutas e V. Aos poucos V., que até então chorava em todas as sessões, foi deixando de lado choro e seu sorriso ocupou este lugar. Mandava beijo (sinal de contentamento segundo a mãe) e participava das sessões respondendo as solicitações com olhar vivo.

Como foi dito anteriormente V. apresentava paralisia cerebral mista quadriplégica severa com importante comprometimento motor e também não possuía sustentação de pescoço. O primeiro contato com V. e com sua família teve o objetivo de conhecer essa criança pelo olhar do cuidador, que era sua mãe. A conversa teve início quando foi solicitado que a mãe contasse sobre quem era sua filha. A mãe de V., sempre muito presente no processo, contou que todos em casa tinham uma ótima relação com V., sobretudo seu irmão mais velho, que possuía uma relação muito estreita com a mesma, e segundo a mãe quando V. estava agitada era quem a acalmava. Contou que $\mathrm{V}$. adorava dançar, que ela demonstrava que compreendia algo através do olhar e do sorriso e que mandava beijo quando estava feliz. Em seguida a mãe relatou que V. possuía hipertrofia de adenóide e por isso engasgava muito e o horário da alimentação era sempre muito perturbado pelo choro, além de ficar gripada constantemente. Quanto a outros aspectos alimentares a mãe de $\mathrm{V}$. disse que possuía muitas dificuldades no momento da alimentação, ela não mastigava, não mordia, empurrava o alimento com a língua para fora da boca, babava muito, e engolia com muita dificuldade.

Foi combinado uma visita domiciliar no horário do almoço. Adentrar na casa da criança expande a visão do terapeuta que pode compreender melhor a rede que a cerca, suas relações, seu modo de vida. Foi servido feijão, arroz, carne e verduras, todos em sua consistência normal e a carne cortada em pedaços. A mãe de V. a apoiava em seu braço, mas a criança ia deitando durante momento da alimentação. Esta colocava uma colher cheia em sua boca e V. não fazia preensão do alimento, nem com lábios, nem com os dentes.

V. vinha para as sessões sempre acompanhada da sua mãe, N. Apesar da dificuldade de construção de relação com V. por causa do seu choro e da dificuldade que esta tinha em se relacionar, com o tempo isso se tornou possível.

A relação com mãe de $\mathrm{V}$. foi sempre satisfatória, N. esteve sempre presente nos atendimentos, passava toda sessão muito atenta ao que era feito, e a ela era explicado os procedimentos e os possíveis benefícios que este traria para V. Participava ativamente, fazia perguntas e contava como tinha sido durante a semana e as "mudanças" que ela percebia, trazia um ar de contentamento e de satisfação com o trabalho. Foi bastante envolvida no processo, N. nos contava que em casa todos (pai e irmãos) a ajudavam. Sempre que percebiam V. com a boca aberta ou babando, estes solicitavam que ela fechasse a boca e engolisse a saliva, segundo N., sua filha sorria e fechava a boca. Certo dia, ao final da sessão ela pediu um pedaço da gaze que havia sido utilizada no trabalho da mastigação e disse que era para fazer em casa, pois ela sempre trabalhava com V. os mesmos exercícios que eram feitos durante a sessão. Essa ação da mãe foi possível pela escolha de trabalhar com um saber compartilhado, naquele momento não tinha sido feito uma orientação, mas o trabalho colaborativo suscitou esse comportamento. A ação foi propulsora de mudanças, com isso a família se sentiu motivada a participar dessa prática e entendeu o seu momento de agir passando a ser interlocutora. Esse afetamento ocorreu no momento em que as ações ganharam corpo e ultrapassaram as orientações. Era notável como a família se desdobrava para garantir uma melhor qualidade de vida a V., chegando ao ponto de substituir os afazeres de casa e o trabalho para que esta fosse estimulada, isso mostrava um envolvimento total da mãe no processo terapêutico e, sem dúvida, foi a interação que permitiu o trabalho conjunto. 
A mãe, desde a primeira entrevista, mostrou-se envolvida com a terapia e comprometida com sua filha, mas dava muitos sinais de que não sabia o que fazer. Com sua presença no processo terapêutico encontrou espaço para o diálogo, para aprender a lidar com as dificuldades da filha. Dentre as mudanças pode-se destacar: a atitude em executar os exercícios em casa; a mudança no oferecimento dos alimentos; a modificação na forma de alimentar.

O terapeuta constantemente se transforma a partir da relação que estabelece com a família e todo o contexto no qual a criança se insere. Junto as família ocorreu a descoberta de anseios, desejos, gostos, bem como coisas que as crianças não gostavam em relação à alimentação. A partir da construção de um conhecimento mútuo, garantido pela confiança e respeito, tornou-se possível estabelecer uma relação entre terapeuta, paciente e família, que viabilizou o início de um trabalho específico de desenvolvimento motor.

\section{CONSIDERAÇÕES FINAIS}

Sabe-se que no dia-a-dia encontram-se formas distintas de lidar com determinadas situações clínicas, diante disso pode-se optar por assumir o papel do que "detém o saber" ou, o de alguém de está disposto a ouvir e a criar conjuntamente formas e estratégias para resolução das dificuldades. Sem dúvida há princípios gerais que regem cada tipo de patologia, como sinais, sintomas e características clínicas que podem ser dominados teoricamente o que poderia justificar a escolha de agir como "aquele que sabe", porém o que faz toda diferença no processo são, justamente, as características pessoais, a forma como cada indivíduo e cada família encontra para lidar com suas dificuldades, que fornecem subsídios norteadores sobre como começar e que caminho seguir no trabalho terapêutico.

Partindo desse pressuposto, neste estudo optou-se pelo trabalho conjunto. Com a participação da família nas sessões buscou-se cultivar o ambiente de pensar juntos e dividir as informações, pois cada membro envolvido detinha um tipo de saber que poderia ser partilhado. Percebeuse que fora do lugar de detentor do saber é mais fácil se colocar ao lado do paciente e da família convidando-os a uma parceria. Essa atitude possibilitou envolver a família no processo terapêutico, entender e identificar as respostas dos usuários, suas características pessoais, permitindo não apenas o trabalho motor oral, mas também o aparecimento de um sujeito.

Após as 15 sessões com Y. e 13 sessões com V. percebeu-se modificações no olhar das famílias quanto ao padrão postural correto para a alimentação, adequação dos utensílios e da forma de oferecer os alimentos à criança, a extensão de ações da terapia para casa, a construção de uma relação de confiança entre terapeuta e família. As famílias passaram a dar maior credibilidade ao processo terapêutico. Neste caso, o trabalho foi focado na Motricidade Orofacial, mas o que objetivamos neste artigo, foi mostrar como a família pode ser incluída no processo terapêutico e a importância dessa participação. Independente da queixa e da patologia a família deve ser vista. Devemos escutar suas demandas, compreender a dinâmica familiar, para que assim possamos agir sobre o processo (MANGIA; BARROS, 2008).

Enfim, pode-se finalizar dizendo que nesse processo é feita a constituição do terapeuta, afetado pelas relações. Mesmo em sujeitos com corpos tão frágeis, com tantas limitações, foi reconhecida a presença de um funcionamento simbólico, que precisava ser ressignificado. Isto é, o trabalho não era só técnico, estávamos diante de crianças que iam aos poucos se tornando sujeitos. Nesta perspectiva, a família não poderia ser deixada de lado, pois nos tornamos sujeitos na relação com o outro e os processos intersubjetivos entre a família e a criança são essenciais. O desafio foi construir um setting fonoaudiológico em que a teoria não servisse apenas para aplicações técnicas sem se deixar afetar pelo sujeito com seu sofrimento. Ao terapeuta cabe a reflexão sobre a sua práxis e o compromisso com sua formação teórica.

GIVIGI, R. C. N.; SANTOS, A. S.; RAMOS, G. O. A new view on the family participation in the therapeutic process. Rev. Ter. Ocup. Univ. São Paulo, v. 22, n. 3, p. 221-228, set./dez. 2011.

\begin{abstract}
This study had the objective of including the family in the therapeutic process of children with cerebral palsy as well as analysing the effects of this inclusion. Methodologically, study cases including two children, one 4 years old and the other 8 years old, who were diagnosed with cerebral palsy of different types and in different stages. The speech therapy was for eight months, once a week. At the end of this period, it was observed a greater involvement of the family in the therapeutic process; a tendency toward dialogue; better identification of the patients' responses; the family identified the patient as a subject. The conclusion is that for therapeutic process with children, the inclusion of the family is essential, and the clinic is a space that provides such environment.
\end{abstract}

KEY WORDS: Family/psichology; Family therapy; Disabled children/psichology; Sepach, language and hearing sciences 


\section{REFERÊNCIAS}

ABBUD, C. A. G.; SANTOS, S. E. C. T. A família na clínica fonoaudiológica e psicopedagógica: uma valiosa parceria. Psicol. Teoria Prat., São Paulo, v. 4, n. 2, p.41-48, 2002.

BAKTHIN, M. Marxismo e filosofia da linguagem. Trad. Michel Lahud, Yara Frateschi Vieira. 8a. ed. São Paulo: Hucitec, 1997.

BARBIER, R. A pesquisa-ação. Brasília: Líber, 2004.

BOBATH, K. Uma base neurofisiológica para o tratamento da paralisia cerebral. 2a. ed. São Paulo: Manole, 1990, p.1-73.

GALHEIGO, S. M.; ANGELI, A. A. C. de. Terapia ocupacional e o cuidado integral a saúde de crianças e adolescentes: a construção do Projeto ACCALANTO. Rev. Ter. Ocup. Univ. São Paulo, 2008, v.19, n.3, p. 137-143, 2008.

GIVIGI, R. C. N. A mediação fonoaudiológica na interlocução entre pais e filhos com dificuldades de linguagem e comunicação. In: NUNES, L. R. O. P.; PELOSI, M. B.; GOMES, M. R. Um retrato da comunicação alternativa no Brasil: relatos de pesquisa e experiências. Pós graduação em educação. Rio de Janeiro: Universidade do Rio de Janeiro, 2007. v. 1, p.287-297.

GOMES, I. C. D. Família e fonoaudiologia. In: MARCHESAN, I. Q. Fundamentos em fonoaudiologia: aspectos clínicos da motricidade oral. 2a. ed. Rio de Janeiro: Guanabara Koogan, 2005. p.133-138.

HENN, C. G.; PICCININI, C. A.; GARCIAS, G. L. A família no contexto da síndrome de Down: revisando a literatura. Psicol. Estud., v. 13, n. 3, p. 485-493, 2008.

KERTÉSZ, R.; INDUNI, G. Manual de análisis transaccional.
Buenos Aires: Editora Conantal, 1977.

LAMELA, D.; NUNES-COSTA, R.; FIGUEIREDO, B. Modelos teóricos das relações coparentais: revisão crítica. Psicol. Estud., v. 15, n. 1, p. 205-216, 2010.

LIMONGI, S. C. O. Processo terapêutico fonoaudiológico na paralisia cerebral. Fonoaudiologia: informação para formação - procedimentos terapêuticos em linguagem. Rio de Janeiro: Guanabara Koogan, 2003. p.67-89.

MANGIA, E. F.; MURAMOTO, M. T. Itinerários terapêuticos e construção de projetos terapêuticos cuidadores. Rev. Ter. Ocup. Univ. São Paulo, v. 19, n. 3, p. 176-182, 2008.

MANGIA, E. F.; BARROS, J. O. Projetos terapêuticos e serviços de saúde mental: caminhos para a construção de novas tecnologias de cuidado. Rev. Ter. Ocup. Univ. São Paulo, v. 20, n. 2, p. 85-91, 2008.

SOUZA, L. V.; SANTOS, M. A. A participação da família no tratamento dos transtornos alimentares. Psicol. Estud., v. 15 , n. 2 , p. 285-294, 2010.

VAL, D. C.; LIMONGI, S. C. O.; FLABIANO, F. C.; SILVA, K. C. L. Sistema estomatognático e postura corporal na criança com alterações sensório-motora. Rev. Pró-Fono. Atual. Cient., v. 17, n. 3, 2005.

WINNICOTT, D. W. Holding e interpretação. São Paulo: Martins Fontes, 1991.

YIN, R. K. Case study research: design and methods. Trad. Ricardo L. Pinto. Adaptado por: Gilberto de A. Martins. Disponível em: <http://www.eac.fea.usp.br/metodologia/ estudo_caso.asp>. Acesso em: 13-09-2010. 2002. 